\title{
Formação de carreiras para a gestão pública contemporânea: o caso dos Especialistas em Políticas Públicas e Gestão Governamenta|*
}

Elisabete Ferrarezi e Adélia Zimbrão

\section{Introdução}

A carreira de Especialista em Políticas Públicas e Gestão Governamental (EPPGG) caracteriza-se pelo exercício de atividades relacionadas à gestão governamental e à formulação, implementação e avaliação de políticas públicas, podendo assumir variadas funções e responsabilidades, como o gerenciamento, a assessoria técnica, a direção ou a coordenação de programas e projetos governamentais. Ela surgiu com base em estudo realizado em 1982, que também recomendava a criação de uma instituição voltada exclusivamente para a formação desses quadros superiores.

A Escola Nacional de Administração Pública (ENAP), criada a partir dessa proposta, passa a desenvolver cursos de formação de longa duração para essa e outras carreiras, como a de Analistas de Planejamento e Orçamento. Em 2003, o curso de formação para a carreira de EPPGG passou por um processo de 
reformulação visando adaptá-lo às mudanças ocorridas na gestão pública, considerando as complexidades da sociedade contemporânea e as exigências de profissional que tenha capacidade de análise, reflexão e tomada de decisão em busca de resultados em prol do cidadão amparado pela ética pública.

O objetivo deste texto é analisar duas edições realizadas desse novo curso de formação e discuti-las tendo em vista os desafios contemporâneos da administração pública. Para tanto, o texto apresenta: histórico da carreira no governo federal; resumo dos cursos de formação realizados entre 1988 e 2004 pela ENAP; análise da reformulação do programa de formação e dos resultados; propostas para a formação continuada para a administração pública contemporânea; e considerações finais.

\section{Breve histórico da carreira de Especialista em Políticas Públicas e Gestão Governamental}

No contexto da redemocratização do País, em meados dos anos 80 o governo do presidente José Sarney (1985-1989) promoveu uma reforma administrativa ${ }^{1}$ com o objetivo de racionalizar e conter os gastos públicos e também dotar os quadros do serviço público federal de pessoal capacitado para corresponder às novas demandas da sociedade que a democracia exigia. Foi assim que a Comissão Geral de Reforma, constituída em 1986, identificou a necessidade de criação de uma escola de governo que promovesse a formação e qualificação de quadros de nível superior para a missão de modernizar e tornar eficiente a Administração Pública Federal (Petrucci, 1995).
A idéia de se implantar no Brasil uma escola superior de administração pública já estava presente num estudo realizado, em 1982, pelo Embaixador Sergio Paulo Rouanet, a pedido do Departamento Administrativo do Serviço Público $(\text { Dasp })^{2}$. Esse estudo apontava que a fragilidade dos quadros da administração pública e a ausência de critérios objetivos para o acesso à alta função pública geravam descontinuidades tanto na execução de reformas administrativas quanto na implementação de políticas públicas. Era necessário formular um sistema que articulasse formação e inserção na alta administração, sem o qual a "[...] escola não se justificaria nem do ponto de vista dos alunos, nem do ponto de vista do Estado" (Rouanet, 1982, p. 80), posto que "seria irracional investir recursos na formação de uma elite administrativa superqualificada e, ao mesmo tempo, bloquear o acesso dessa elite, em condições duráveis, a seus quadros de direção superior, privando-se assim de todos os benefícios do investimento realizado” (RouAnet, 1982:84).

Assim, o relatório Criação no Brasil de uma Escola Superior de Administração Pública (1982) recomendou a criação de carreira, ou cargos de natureza especial, para o exercício de atividades de direção, supervisão e assessoramento nos escalões superiores da burocracia, como solução para a alocação dos egressos da futura escola ${ }^{3}$. As recomendações desse relatório influenciaram a concepção da ENAP e a constituição de uma carreira para seus egressos, a de EPPGG. No entanto, as duas propostas não aconteceram de forma conjunta, como aconselhou Rouanet. $\mathrm{O}$ projeto de criação da carreira percorreu caminhos bastante tortuosos, enfrentando o efeito de estratégias neutralizantes de grupos políticos e de corporações de 
servidores públicos contrários à nova carreira, pois não queriam repartir seus espaços de poder (Petrucci et al.,1995, p. 99). Assim, a ENAP ${ }^{4}$ foi criada em 1986 e a carreira de EPPGG ${ }^{5}$, em 1989.

A Sedap, que vinha promovendo a Reforma Administrativa da Nova República, tinha como projeto-vitrine a criação da ENAP e da carreira de EPPGG, e sua intenção era implantá-lo antes do término do governo. Por isso, mesmo estando incompletos o projeto pedagógico e curricular da ENAP e o processo de legalização da carreira, a Sedap resolveu abrir concurso público. Desse modo, a homologação do resultado final do curso de formação da primeira turma da escola foi anterior à data do decreto de regulamentação ${ }^{6}$ da carreira.

Para atender à expectativa de perfil generalista para a formação do EPPGG, presente desde a concepção inicial da carreira, a ENAP combinou as características dos administradores civis franceses com as dos analistas de política americanos ${ }^{7}$. Os egressos da escola não seriam especializados em temas determinados e teriam uma formação inter e multidisciplinar que os capacitasse "a identificar problemas e gerenciar soluções, convocando e intermediando as diversas competências especializadas requeridas, interpretando e analisando propostas de especialistas" (PetrucCI et al.,1995, p. 103). Nesse sentido, o curso deveria formar um profissional capaz de ter uma visão abrangente, sistêmica e integrada dos complexos problemas da administração pública.

Previa-se para esses profissionais uma atuação de forma matricial, considerada bastante inovadora, na qual guardariam uma razoável mobilidade institucional, com a carreira inserida horizontalmente em todos os ministérios. Os "gestores", como

ficariam conhecidos seus membros, seriam distribuídos entre os diversos órgãos da administração direta e autárquica e constituiriam a ligação entre os governantes e a máquina burocrática.

Entretanto, a concepção generalista de carreira sofria fortes restrições da Seplan ${ }^{8}$, inclusive de seus dirigentes, que se posicionaram explicitamente contra essa proposta. Em 1990, a reforma administrativa do governo do presidente Fernando

"Para atender à expectativa de um perfilgeneralistapara aformaçãodo EPPGG, presente desde a concepção inicial da carreira, a ENAP combinou características dos administradorescivis francesescom dos analistas de política americanos".

Collor proibiu a realização de concursos públicos. Desse modo, o processo de implementação da carreira, que já vinha sofrendo descontinuidade na gestão do Presidente Sarney, foi interrompido e o cronograma de provimento dos cargos abandonado? .

A possibilidade de retomada do processo de seleção e formação de quadros dirigentes se deu a partir de 1994, 
nos programas de governo dos principais candidatos à Presidência da República, que enfatizaram a necessidade de recuperação da capacidade de governo e a importância da valorização da formação da alta administração pública, por meio da ENAP.

Com a vitória de Fernando Henrique Cardoso para a Presidência, teve início um processo de rearranjo institucional do Estado brasileiro, cuja justificativa estava pautada na crise do papel do Estado. As mudanças na estrutura organizacional e administrativa pretenderam redefinir o papel do Estado e sua forma de se relacionar com a sociedade ${ }^{10}$.

Nesse contexto de mudança, a profissionalização da alta burocracia e a adequação dos recursos humanos foram consideradas uma das tarefas prioritárias da reforma, o que propiciou a realização de concursos para a renovação do quadro de servidores públicos e a reorganização das carreiras e dos cargos. A carreira de EPPGG foi reativada pelo Ministério da Administração Federal e Reforma do Estado (Mare), em 1995, que novamente assumiu uma missão reformista. O Mare elaborou um cronograma de concursos para a carreira, que cobria os quatro anos do mandato do governo, sendo realizados processos de seleção de 1995 a 1998, que constituíram a segunda, terceira, quarta e quinta edições do curso de formação da ENAP ${ }^{11}$.

A reforma ministerial, realizada no início do segundo mandato do presidente Fernando Henrique, extinguiu o Mare e suas atribuições foram transferidas para a Secretaria de Gestão, do Ministério do Planejamento, Orçamento e Gestão. Essa mudança assinalou a perda de força e prestígio da reforma administrativa, gerando a suspensão dos concursos por um ano, que foram retomados em 2001 e 2002, para a formação da $6^{\mathrm{a}}$ e $7^{\mathrm{a}}$ turmas. Mesmo com a mudança de governo, que conduziu à Presidência da República Luiz Inácio Lula da Silva, o concurso foi realizado, sendo constituídas a $8^{\text {a }}$ e a $9^{a}$ edições do curso de formação na ENAP, em 2004.

\section{Os cursos de formação inicial para a carreira de EPPGG}

A ENAP, até 2004, realizou nove edições do curso de formação inicial para a carreira de EPPGG ${ }^{12}$. Essas edições serão concisamente analisadas com base nos problemas apontados pelos alunos e pelas coordenações dos cursos, registrados nos relatórios finais disponíveis para consulta. De modo geral, podem-se categorizar essas edições em quatro momentos, relacionados ao contexto político de cada período de sua realização.

O primeiro momento é constituído pela experiência isolada da primeira turma, que se deu na conjuntura de redemocratização do País, no final dos anos 80. Essa fase foi marcada fortemente pelo discurso de que a ENAP formaria uma elite administrativa para atuar nos altos escalões da administração pública, constituindo uma burocracia moderna, estável, competente e preparada para os desafios do País e da democracia nascente. Embora a intenção fosse desenhar um curso que atendesse a essas expectativas transformadoras, vários problemas impediram que o curso tivesse a dimensão política e a organicidade pretendidas.

Com início em agosto de 1988, o curso pioneiro de formação em políticas públicas e gestão governamental recebeu os 120 candidatos classificados na primeira fase, que tinham expectativas elevadas quanto ao 
curso e a sua futura carreira. Conforme Petrucci (1995, p.101), eles "Atendiam à convocação da Escola para a capacitação de uma elite administrativa, mediante curso de formação primoroso, com corpo docente altamente qualificado e instalações físicas excelentes, além de bolsa de estudos durante os 18 meses do curso". Entretanto, as expectativas logo foram revertidas, porque o valor da bolsa não passava da metade do esperado, houve "certa dose de improvisação" nas primeiras etapas do curso e ainda não estava legalizada a carreira que os absorveria. Os alunos tiveram ainda de se mobilizar para a aprovação da lei de criação da carreira, articulando-se com lideranças do Congresso Nacional e com altos escalões da burocracia.

O curso foi desenvolvido em horário integral, ao longo de 18 meses, com uma carga horária de 2.800 horas. Por não dispor de um corpo permanente de docentes, a ENAP contratou professores de importantes instituições de ensino e pesquisa do País, assim como profissionais experientes do governo federal. Em sua estrutura original, a formação contemplava três etapas sucessivas e articuladas: embasamento (1.300 horas), estágio (mil horas) e complementação (500 horas).

A primeira etapa, embasamento, era formada pelos blocos de integração; fundamentos; prática de políticas públicas; instrumentos de gestão; instrumentos de pesquisa; análise de conjuntura; e língua estrangeira. Tinha como objetivos integrar os alunos à ENAP e nivelar os conhecimentos em função das formações diferenciadas; ampliar a visão de mundo dos futuros gestores, por meio do aprofundamento de estudos interdisciplinares, abrangendo conteúdos básicos em ciências humanas, e por meio do desenvolvimento de práticas e instrumentos de gestão e de pesquisa, capazes de assegurar a relação entre teoria e prática.

$\mathrm{Na}$ segunda etapa do curso, havia o estágio em órgãos públicos, visando ao aprendizado dos alunos em situações concretas da administração pública, e, por último, a etapa de complementação, um período de ensino personalizado com o objetivo de preencher eventuais lacunas deixadas pelas etapas anteriores. No entanto, essa etapa foi reestruturada, pois foram detectadas carências teóricas e conceituais significativas nas fases anteriores e nos métodos de análise de políticas públicas. A mudança consistiu na realização de cursos intensivos sobre vários temas, com carga horária de até 80 horas e participação obrigatória de todos os alunos. $\mathrm{Na}$ segunda parte, organizada em pequenos módulos simultâneos sobre áreas específicas de gestão, os alunos poderiam selecionar os de seu interesse (Petrucci, 1995).

Ao final dos seis primeiros meses, os alunos fizeram uma avaliação do curso e sugeriram diversas alterações, entre as quais a reorganização curricular. Dentre os principais problemas por eles identificados destacam-se: a preparação do curso ter-se dado concomitantemente à sua realização, devido ao caráter emergencial, e a contratação dos professores sem elaboração prévia das ementas curriculares $^{13}$; a falta de integração dos conteúdos, resultando numa compartimentação estanque dos blocos formativos; descompasso entre a estrutura curricular e o desenvolvimento de perfil generalista compatível com as funções que os gestores iriam exercer; trato superficial e repetitivo dado aos sconteúdos no bloco de fundamentos; ausência de abordagens ditas "reais" nas atividades; e qualificação dos professores inadequada às especificidades do curso (Relatório Comissão dos Alunos, 1989). Quanto à ENAP, foram identificados 
problemas nas condições da infra-estrutura oferecida e os alunos tiveram relacionamento difícil com a direção da escola, principalmente por causa das várias mudanças dos diretores ${ }^{14}$ que participaram inicialmente do projeto.

Como se observará adiante, vários desses problemas repetir-se-ão em outros cursos, pois não foram equacionados. Dizem respeito a questões estruturais, como a ausência de quadro próprio de professores, o que dificulta a construção e aplicação de um plano pedagógico específico para formação profissional de servidores e gera descontinuidades, fragmentação ou superposição de temas. Questões como ausência de um sistema de informações e gestão do conhecimento, além do constante esvaziamento dos quadros de servidores da escola também são fatores que influenciaram na recorrência dos problemas, como se verá.

Após longo período de proibição de realização de concursos públicos, em 1995, o então ministro da Administração e Reforma do Estado Bresser Pereira retomou-os com alterações no processo de recrutamento e seleção para EPPGG e Analistas de Planejamento e Orçamento. Para Bresser Pereira, o modelo de recrutamento e formação deveria aproximarse do modelo norte-americano, "[...] que recruta seus altos administradores nos cursos de pós-graduação existentes no país [...]" (ENAP, 1998, p. 275). O novo concurso continuaria sendo desenvolvido em duas fases, mas com grau de dificuldade no nível de pós-graduação.

O curso de formação inicial, realizado em 1996, teve mudanças significativas: a retirada do estágio, uma grande redução da carga horária em relação ao primeiro curso (de 2.800 horas/aula para 900 horas / aula) e ênfase acentuada da Administração
Gerencial em todo o conteúdo programático. A estratégia consistia em ter um número significativo de novos funcionários qualificados formados pela Escola de Governo, que seriam espalhados pelos ministérios, disseminando nova cultura na gestão pública.

O segundo momento na história dos cursos realizados para formar a segunda, terceira, quarta e quinta turmas de EPPGG tem como característica principal a orientação para a formação de agentes de mudança da "cultura burocrática tradicional ${ }^{15 "}$ " para a "gerencial", no âmbito da Reforma Gerencial do Mare, com base no discurso do expert em gerência, administração e avaliação. Houve forte ênfase em micro e macroeconomia, finanças públicas, além da New Public Management, para viabilizar a reforma do Estado.

O curso de 1996, de 900 horas, que formaria a segunda turma, foi estruturado em duas partes. A primeira, com duração de cinco meses e meio, contemplou atividades introdutórias, os blocos economia do setor público, políticas e governabilidade, administração pública e governança, ciclo de conferências e atividades complementares. A segunda parte, de três meses, foi constituída por um ciclo de atividades discentes complementares, de caráter prático-teórico, em que os alunos deveriam realizar diagnósticos institucionais e propostas de soluções, cujos trabalhos foram examinados por bancas avaliadoras. Dos 70 alunos classificados para o curso de formação, 56 concluíram e 52 tomaram posse no cargo.

A terceira edição do curso, realizado em 1997, manteve, em linhas gerais, a estrutura da segunda, sofrendo alguns ajustes de carga horária, em razão das dificuldades encontradas pela turma em determinadas disciplinas, o que levou à 
realização de nivelamento em Economia e Ciência Política. O curso teve um total de 912 horas. Dos 115 matriculados no curso (de 130 vagas), foram aprovados 96 e 84 ingressaram na carreira.

Em março de 1998, em razão do ano eleitoral, o quarto curso de formação foi dividido em duas etapas. A primeira, com 446 horas, aprovou 106 candidatos dos 120 classificados na primeira fase do concurso; e a segunda, com 384 horas, realizada após a nomeação e posse dos aprovados na primeira etapa da formação, que tiveram de voltar à escola para concluir o curso com o ciclo de atividades complementares. O curso manteve, no geral, a estrutura das edições anteriores, reduzindo a carga horária da primeira parte.

O quinto curso, realizado em 1999, teve 900 horas e 140 vagas, o que resultou na constituição da maior turma de formação inicial até o momento. O programa do curso foi elaborado praticamente com a mesma estrutura em blocos das edições anteriores, mas o relatório revela um hiato entre o planejado e o executado. Durante a realização da formação dessa turma, o Mare foi extinto, enfraquecendo a Reforma Gerencial. Seus efeitos foram sentidos no curso, que, segundo a opinião dos alunos, foi perdendo a conexão entre as disciplinas. Nessa experiência houve problemas similares aos levantados pelos alunos nos cursos anteriores, mas o caráter eliminatório, segundo a quinta turma, ganhou destaque especial da direção da escola, como forma de reduzir o número atípico da turma.

Sob a perspectiva dos alunos, durante esse segundo momento, destacam-se as seguintes questões críticas, presentes em maior ou menos grau em cada uma das edições: a competição entre os participantes, desencadeada pelo caráter classificatório do curso (que propiciava a escolha da instituição na qual iriam trabalhar), gerava um clima de ansiedade, rivalidade e tensão, com atritos constantes entre os alunos, a direção da escola e o órgão gestor da carreira (Ministério do Planejamento); conflitos com alguns professores em razão da falta de didática ou desconhecimento das regras sobre as quais se deveria pautar o concurso; pouco tempo para a leitura da bibliografia obrigatória, considerada excessiva; indisponibilidade de material didático previamente; informações imprecisas; fragmentação do curso, repetição de conteúdos e falta de conexão entre as temáticas; desequilíbrio na ênfase dada em certas escolas/vertentes e em certos conteúdos muito acadêmicos, como macroeconomia e microeconomia, com pouca clareza quanto à aplicabilidade deles; sobrecarga de exercícios extraclasse e excessiva carga horária em sala de aula; ausência de relação entre teoria e prática; e muita ênfase nas avaliações de aprendizagem, que não tinham critérios padronizados e ressaltavam o aspecto "concurso" em detrimento da formação; infra-estrutura da ENAP considerada deficitária.

Durante esse período, percebe-se que a sobrecarga de trabalho e o estímulo à competição, embora tivessem a intenção de preparar os alunos para os desafios que iriam encontrar em certos cargos da administração, o que também tornava mais valorizada essa formação profissional, acabavam prejudicando a aprendizagem e dificultando as relações interpessoais. Essa pressão constante a que estavam submetidos os gestores acabou ofuscando o mérito da retomada do concurso e da formação, bem como da revitalização da Escola empreendida pela direção à época.

A sexta e a sétima turmas estão contidas no terceiro momento e têm uma diferença em relação aos cursos 
anteriores: a ênfase no Plano Plurianual. No segundo mandato do presidente Fernando Henrique Cardoso, o Plano Plurianual 2000-2003 ganhou destaque, assumindo o lugar que antes era ocupado pelas idéias da reforma do Estado. Comparando-se com os anteriores, os cursos foram mais desestruturados no que diz respeito ao ordenamento e à lógica na disposição das disciplinas, não mais agrupadas por blocos. Pode-se inferir que a extinção do Mare e o conseqüente enfraquecimento da reforma administrativa entre 2001 e 2002 tiveram impacto sobre essas edições da formação. A sétima edição ${ }^{16}$ ocorreu em ano eleitoral, tendo como conseqüência a redução da carga horária da primeira etapa do curso de formação para 272 horas. A segunda etapa, o Ciclo de Atividades, com 640 horas, foi realizada após a nomeação e posse dos gestores. Entre as atividades havia o estágio com participação ativa da ENAP. As principais críticas dos alunos, nesse terceiro momento, são praticamente as mesmas do período anterior.

$\mathrm{E}$, por fim, o quarto momento, em que se encontram a oitava e a nona edições do curso de formação para EPPGG, que serão tratadas no próximo item. Esse momento marca uma inflexão na formação propiciada por uma reformulação geral no programa e na gestão dos processos de trabalho da coordenação de formação de carreiras e pelo enfrentamento de questões ${ }^{17}$ consideradas essenciais para a melhoria das relações interpessoais entre os alunos, os docentes e a Escola.

\section{A reformulação dos cursos de formação inicial}

Em 2003, no início do governo Lula, o curso de formação inicial para a carreira de EPPGG passou por um processo de reformulação pela nova equipe, com base na análise dos programas das edições anteriores, nas avaliações de reação dos alunos e no diálogo com professores e profissionais que ministraram ou acompanharam várias edições, na tentativa de resolver os principais e recorrentes problemas.

Além de responder à necessidade do perfil generalista e de combinar de forma equilibrada formação e seleção, teoria e aplicação - problemas constantes dos cursos de formação -, era preciso mudar a imagem negativa que a maioria dos EPPGG egressos do curso tinham da Escola, em razão da experiência anterior.

Já que a tensão é inerente a um concurso público e não poderia ser evitada e sendo agravada pela alta exigência em relação aos conhecimentos e às habilidades requeridos, em relação à carga de leitura e aos exercícios, à avaliação de desempenho, etc., era preciso, ao menos, lidar de forma diferente com isso. Nesse sentido, particular atenção deveria ser dada à construção da interlocução e da confiança, à negociação de conflitos, às regras e aos critérios objetivos para aferição de aprendizagem e à criação de ambiente cooperativo para que a aprendizagem pudesse ocorrer de forma mais tranqüila. No que se refere à metodologia de ensino, houve preocupação de oferecer condições de estudo dos conteúdos sem exercer uma excessiva pressão sobre os alunos, que marcou negativamente as edições anteriores.

O baixo alinhamento das ementas feitas por professores com o programa da formação e a pouca coerência interna dos temas, com redundância ou fragmentação de conteúdos - problemas de difícil resolução, já que todos os professores são de outras instituições - , também deveria ser atacado. Por fim, a excessiva carga horária de aulas, a sobrecarga de leitura e a ênfase 
em conteúdos estritamente acadêmicos com pouca aplicação e reflexão sobre a prática.

O conjunto de temas propostos para a formação da oitava e nona edições teve por base as competências genéricas ${ }^{18} \mathrm{da}$ carreira, consideradas fundamentais pela ENAP, tendo em vista as características de transversalidade das atividades e o perfil generalista do EPPGG, o que exige que se trabalhe com múltiplas competências. Além disso, não seria possível desenvolver todas as competências necessárias à consecução dos objetivos estratégicos das várias organizações em que os EPPGG trabalham, tendo de se concentrar em habilidades e conhecimentos que sejam úteis e válidos para a maioria das situações.

A concepção do programa do novo curso partiu, assim, das competências do núcleo comum da carreira para o desempenho da gestão governamental e para a elaboração, implementação e avaliação de programas e projetos. Com esse conjunto de funções, supõe-se que o EPPGG deve possuir visão ampla, sistêmica e integrada dos problemas socioeconômicos e político-administrativos da Administração Pública Federal e das relações desta com a sociedade. O EPPGG atua em áreas diversificadas, de forma matricial, com mobilidade institucional e deve estar apto para enfrentar os desafios do setor público (capacidade de analisar e decidir) ${ }^{19}$.

Espera-se que esse profissional seja capaz de assimilar criticamente as mudanças e adaptar-se a elas e que auxilie e promova inovações organizacionais e utilize técnicas de gestão eficazes e eficientes, tendo sempre em vista a promoção dos direitos do cidadão e o compromisso com o alcance de resultados na administração pública (capacidade de buscar resultados).
A expectativa é de que esse profissional contribua para a formação de uma burocracia competente, compatível com os desafios da democracia e da promoção do desenvolvimento, e conduza as relações e as atividades profissionais de acordo com princípios éticos (valores da ética pública).

Dentre as principais mudanças na oitava e nona edições do curso, destacam-se:

- a adequação dos conteúdos e da carga horária aos objetivos de uma capacitação

"Aomesmotempo em que a formação de servidorestenta resoberproblemas contemporâneos, ela também deveolbar paraofutura. As onganizaçõeseas pessoasprecisamestar dispostas a aprender contimamente, a fim de dimimir a defasagem, própriadadinâmica organizacional, entre as competências atuaise asnecessárias”.

singular, que alia formação profissional e concurso público, mas cuja ênfase é a criação de ambiente favorável à aprendizagem;

- o novo encadeamento das disciplinas, organizadas por eixos estruturantes que integram os conteúdos diversificados e os articula em função dos objetivos gerais do curso e de um tema gerador;

- a elaboração, pela coordenação, de programa detalhado do curso, chegando-se 
às ementas e aos objetivos de aprendizagem e tentando orientar e alinhar o plano de aula desenvolvido pelo professor à proposta da ENAP;

- a obrigatoriedade de utilização pelos professores de critérios padronizados, estabelecidos pela coordenação, para todas as avaliação de aprendizagem;

- as estratégias didáticas que privilegiam um ensino mais dinâmico e aplicado, com o uso de oficinas para exercitar algumas situações de transposição e aplicação do conhecimento, trabalhos orientados com carga horária destinada à leitura obrigatória e à realização de trabalhos durante as aulas;

- o estabelecimento de regulamento, padrões operacionais básicos e processos de trabalho mais profissionalizados para a equipe de coordenação, apoio administrativo e secretaria escolar, com padrões de atendimento ao aluno;

- as regras mais objetivas para a relação com o professor, que deve cumprir com as obrigações estipuladas: envio antecipado do plano de aula e de bibliografia, contendo a definição de exercícios e avaliações de aprendizagem para análise da coordenação, que realiza ajustes de acordo com o programa do curso; utilização de critérios de avaliações definidos; utilização das orientações didáticas e metodológicas básicas emanadas pela ENAP;

- o acompanhamento das aulas pelos coordenadores de curso, a fim de permitir diálogo com o professor sobre a necessidade de alterações na programação ou na metodologia e para acompanhar o desenvolvimento dos alunos;

- a intensa comunicação da coordenação com os alunos (via Internet e em sala de aula), a fim de garantir que as informações e eventuais mudanças cheguem a todos e para estabelecer um canal direto para ouvir as reivindicações, reclamações, sugestões e dúvidas dos alunos;

- a realização de três tipos de avaliação de reação pelos alunos: por disciplina, por eixo (módulo) e final. Os resultados de cada disciplina são encaminhados aos professores como feedback de suas atividades ${ }^{20}$.

Como resultado, formulou-se um programa curricular com uma carga horária em torno de 450 horas/aula ${ }^{21}$, desenvolvido em cerca de três meses e meio. As aulas são ministradas em regime de tempo integral, com jornada diária de trabalho de oito horas, o que se tornou possível pela concessão de bolsa de estudos durante a realização do curso.

Além do objetivo geral de selecionar e preparar quadros de alta gerência para o ingresso na Administração Pública Federal, em conformidade com a política estabelecida pelo órgão supervisor da carreira o Ministério do Planejamento, Orçamento e Gestão/Secretaria de Gestão, o curso, após o seu término, deveria capacitar o aluno a utilizar marcos teóricos e instrumentos necessários ao desempenho das atividades inerentes ao cargo, considerando suas múltiplas dimensões.

São objetivos específicos do curso de formação inicial (ENAP, 2004):

- favorecer o desenvolvimento da capacidade do aluno de trabalhar os conhecimentos de forma multi e interdisciplinar, visando à identificação de problemas prioritários e de alternativas de solução para a tomada de decisões;

- proporcionar oportunidades de conhecimento e aplicação de instrumentos compatíveis com a gestão estratégica das organizações públicas;

- desenvolver habilidades necessárias para coordenação, formulação, elaboração, implementação e avaliação de políticas públicas; 
- fomentar habilidades do aluno para a promoção de redes e parcerias entre diferentes níveis de organizações governamentais, da sociedade e do setor privado, visando potencializar o impacto das políticas públicas e programas governamentais;

- favorecer a capacidade de trabalhar em equipe;

- proporcionar o debate atual sobre temas estratégicos na administração pública para a promoção do desenvolvimento;

- incentivar a adoção de atitudes éticas compatíveis com o desempenho da função pública.

A organização programática em quatro eixos básicos, que são integrados entre si e cujos temas também dialogam internamente no eixo, buscou conferir coerência lógica e seqüencial ao programa. A própria idéia de "eixo" traduz a expectativa de que o curso tem uma linha principal claramente definida, que se divide em partes equilibradas e as articula em função de uma direção. No caso, o foco foi a promoção da eqüidade e do desenvolvimento humano e social sustentável.

A formação inicia-se com um ciclo de palestras com os objetivos de integração entre as participantes, de aproximação da realidade da administração pública por meio de seminários com dirigentes e encontros com EPPGG e de transmissão de informações sobre as principais diretrizes e políticas para a Administração Pública Federal e sobre o curso e a carreira. Também há um ciclo de seminários durante o curso, voltado ao debate de temas candentes, inovadores ou polêmicos, à disseminação de novos referenciais e propostas, à consolidação ou ampliação dos conteúdos e práticas desenvolvidos nos eixos programáticos e a temas pertinentes à agenda de governo.
Os eixos tratam dos principais temas e problemas relacionados ao Poder Executivo, enfatizando conhecimentos, marcos analíticos, informações e tecnologias de gestão aplicáveis ao setor público, incentivando o desenvolvimento de competências que permitam pensar, agir e interagir estrategicamente com vista à busca de resolução de problemas e de melhores resultados em prol do cidadão. Além disso, o curso deve propiciar, ao novo integrante, o acesso a informações de forma que este tenha maior familiaridade com a situação de trabalho na administração pública, com a sua estrutura organizacional e modo de funcionamento. Os eixos são: Estado, sociedade e democracia; Economia e desenvolvimento; Administração pública; Políticas públicas ${ }^{22}$.

Os objetivos gerais definidos para os eixos são (ENAP, 2004):

Eixo 1: Estado, sociedade e democracia - Refletir sobre as transformações do Estado contemporâneo e as mudanças nas relações entre o Estado e a sociedade, o sistema político brasileiro, a estrutura e o funcionamento do Estado brasileiro e sobre a organização política da sociedade no processo de construção e fortalecimento da democracia e da extensão da cidadania;

Eixo 2: Economia e desenvolvimento - Situar o debate econômico atual e as perspectivas da economia brasileira, refletir sobre condicionantes, possibilidades e dificuldades para a atuação do Estado na formulação das políticas públicas e sobre as teorias e evidências associadas ao debate sobre o desenvolvimento;

Eixo 3: Administração pública Desenvolver os marcos teóricos necessários a uma compreensão crítica da administração pública contemporânea, conhecer sua organização e principais 
sistemas, fornecer instrumentos operacionais básicos para a atuação no cargo;

Eixo 4: Políticas públicas - Conhecer os principais marcos teóricos da análise das políticas públicas e refletir sobre eles, incentivar o desenvolvimento de habilidades para o uso de instrumentos básicos necessários ao desenho, à implementação e à avaliação das políticas públicas.

Para cada eixo foram ainda definidos os objetivos específicos e as ementas e, para cada disciplina, os objetivos de aprendizagem. Um resumo dos temas que compõem os eixos é apresentado no final deste artigo.

O oitavo e o nono cursos de formação inicial foram muito bem avaliados nos três tipos de avaliação realizados (em cada uma das disciplinas, ao final dos eixos e ao final do curso). A melhora significativa em relação aos problemas anteriores decorreu das mudanças realizadas com base no enfrentamento de vários problemas diagnosticados pelos próprios alunos ${ }^{23}$. Embora com altos desvios padrão, em decorrência da grande heterogeneidade na formação acadêmica e nas expectativas dos alunos, as médias gerais obtidas, apenas na avaliação final, foram 7,37 e 7,39 para o oitavo e o nono cursos respectivamente. Essa avaliação final trata da satisfação geral do aluno quanto a um conjunto de aspectos, divididos em três temáticas: programação (oitavo curso - média 7,0; nono - média 7,0); coordenação e apoio da ENAP (oitavo curso - média 8,0; nono - média 7,5); e resultados esperados e aplicabilidade (oitavo curso - média 7,3; nono - média 7,5). Também nos outros tipos de avaliações realizados, em geral, os professores, seus métodos e o programa foram muito bem avaliados pelos alunos.

A fim de garantir a qualidade e o cumprimento dos objetivos de aprendi- zagem, a coordenação de formação de carreiras deu a direção do curso. Tinha de garantir os padrões estipulados, orientar e monitorar os professores ${ }^{24}$ que receberam orientações sobre as características da carreira e do programa do curso/concurso, sobre o regulamento e sobre os critérios de avaliação que deveriam ser adotados.

Assim, a autonomia que os professores contratados tinham anteriormente diminuiu e aumentou o grau de intervenção e a responsabilidade da equipe coordenadora na condução do curso. Essa mudança foi necessária porque a Escola não dispõe de corpo permanente de docentes e, embora os professores sejam de alto nível, de importantes instituições de ensino e pesquisa do País e experientes profissionais da máquina burocrática, em geral não dispõem de suficiente preparação metodológica para o ensino aplicado, que permitisse apresentar conhecimentos na forma de casos práticos, baseados em atividades reais, que deveriam caracterizar esse curso. Reside aí um grande problema que deverá ser enfrentado, porque compromete muito o trabalho de escolas de governo que não têm corpo docente mínimo.

As informações aos alunos sobre as regras e o funcionamento do curso foram constantemente enfatizadas, tendo em vista tratar-se de concurso público. Sempre que possível foram feitos remanejamentos de prazos para entrega de trabalhos, tendo em vista o grau de dificuldade e o volume de textos. A publicidade de informações e regras e a relação de confiança que se estabeleceu entre os alunos e a coordenação contribuíram certamente para a melhoria de qualidade do curso. O material didático entregue antecipadamente ao aluno, organizado por disciplina, é composto do roteiro das aulas com a seqüência dos conteúdos, o cronograma do curso, os objetivos de 
aprendizagem, a forma de avaliação a ser adotada, os prazos de entrega de trabalho e os textos de leitura obrigatória.

O acompanhamento dos alunos e professores, em sala de aula, pelo coordenador de curso, embora ainda não suficiente, representou um diferencial significativo em relação às edições anteriores. A limitação, nesse caso, refere-se ao número de pessoas para supervisão pedagógica, pequeno se considerar a complexidade das atividades de gerenciamento a cargo do coordenador de curso. A autonomia da equipe para fazer eventuais mudanças na programação, com o professor, sempre que se estivesse desviando ou se sobrepondo ao que já havia sido ministrado, e o diálogo constante com os professores para ajustes nos recursos instrucionais e na metodologia puderam ser feitos durante o período em que estavam sendo desenvolvidas as aulas, evitando-se que situações problemáticas se estendessem.

\section{A formação continuada para a administração pública contem- porânea}

No início do século XXI, os problemas do setor público - principalmente aqueles relacionados à gestão de recursos, eficácia dos resultados, eficiência e relação com os cidadãos - ficaram mais complexos. Nesse contexto, a questão da formação dos servidores exige novas perspectivas, haja vista que a maioria das pessoas não foi preparada para analisar a enorme produção de conhecimentos e informações e para lidar com ela, com a quebra de paradigmas e comas exigências de reflexão constante para a busca de soluções dos problemas. Como formar alguém não só para exercer habilidades e ter mais instrumentos, mas, sobretudo, para estabelecer parâmetros éticos, intelectuais e políticos para suas ações? Como estimular a reflexão e o uso de informação e conhecimento disponíveis para a crítica e solução de problemas (Nogueira, 2004)?

Para que a capacitação tenha eficácia e impacto sobre o trabalho, é preciso ter claro o seu alcance, o que significa identificar que problemas ela quer resolver ou que competências quer desenvolver. Ela não resolve todos os tipos de problemas da organização, mas somente aqueles que foram diagnosticados como passíveis de resolução por meio de capacitação ${ }^{25}$.

Ao mesmo tempo que a formação de servidores tenta resolver problemas contemporâneos da sociedade, que constam da agenda política, ela também deve olhar para o futuro. Desse modo, as organizações e as pessoas precisam estar dispostas a aprender continuamente, a fim de diminuir a defasagem, própria da dinâmica organizacional, entre as competências atuais e as necessárias. Por esse motivo, a tarefa torna-se ainda mais desafiadora, uma vez que, no Brasil, acumulam-se na agenda tanto os aspectos diagnosticados pelas primeiras gerações de reformas administrativas, não plenamente resolvidos, quanto aqueles ligados aos novos problemas e às novas demandas da sociedade.

Em uma sociedade cuja diversidade é crescente, as expectativas são cada vez maiores, individualizadas e com vários meios de vocalização, se comparadas às do passado, o papel do servidor também será incomensuravelmente mais complexo (Trosa, 2001). Tendo em vista essas mudanças e as novas exigências colocadas para a administração pública, decorrentes da complexificação das sociedades e dos Estados contemporâneos, e com base na 
oitava e nona edições do curso de formação para EPPGG, em que pudemos experimentar algumas das propostas a seguir relacionadas, apresenta-se, para discussão uma lista não exaustiva dos requisitos que poderiam compor programas de capacitação para a alta função pública e incluir estímulos aos servidores para o seguinte:

- ter como base para decisões e ações os parâmetros éticos, sociais, culturais e políticos e instruir a gestão pública por princípios de eqüidade e de democracia;

- estimular a reflexão e o uso de informação e conhecimento disponíveis para a crítica e solução de problemas e, sempre que possível, realizar consultas à sociedade para amparar as decisões;

- ser um "tradutor cultural" (Trosa, 2001), capaz de compreender diferentes funcionamentos e lógicas e dialogar com as múltiplas identidades societárias, com atenção especial às questões de etnia e de gênero;

- estimular a compreensão sobre o alcance da ação do servidor, que tem como finalidade última o desenvolvimento social sob a ótica dos direitos do cidadão. Nem como súdito nem como beneficiário, o cidadão tem o direito a ter todos os direitos e deve ser tratado como sujeito de sua cidadania;

- possibilitar a reflexão dos servidores públicos sobre suas próprias práticas, buscando inserir, apesar dos constrangimentos conjunturais ou estruturais, os elementos da criatividade, do empoderamento da comunidade, do diálogo político em suas rotinas e accountability;

- compreender as relações intrínsecas entre política, desenvolvimento e mudança social;

- buscar novas formas de articulação das políticas descentralizadas, criando capacidade para a gestão de múltiplas e diferentes redes e a coordenação transversal de programas no âmbito da Federação, integrando e fortalecendo o fluxo de informações, propostas e soluções características da sociedade-rede;

- incentivar a participação de atores locais e setoriais na esfera pública, estimular a conexão horizontal entre organizações públicas, privadas e comunidades, democratizando procedimentos e processos decisórios, liberando o potencial político e empreendedor dos atores e apontando para diferentes arranjos e equilibrio entre Estado, setor privado e terceiro setor;

- saber utilizar ferramentas gerenciais mais adequadas à negociação de projetos e de conflitos, à gestão de riscos, à tomada de decisões, ao planejamento, à elaboração de cenários e de contratos, etc.;

- promover a inovação. A porosidade democrática e o experimentalismo público, com responsabilidade ética, devem ser cada vez mais incentivados, tendo-se a flexibilidade como contrapartida de maior responsabilidade e autonomia.

Essas propostas ${ }^{26}$, se desenvolvidas, teriam vários desdobramentos, irradiando outras ações, de acordo com a complexidade do serviço. Pressupõem a vontade política de se construir um Estado não paternalista, não assistencialista e não clientelista. Além disso, a gestão de pessoas, com seus componentes 'gestão' e 'desenvolvimento de competências', deve deixar de ser vista como pertencente à área de recursos humanos para se tornar instrumento do gerente intermediário na administração pública. O meio mais poderoso para mudanças nas organizações é investir nas pessoas.

Tomem-se alguns exemplos da lista anteriormente citada. Para negociar e gerenciar um contrato de terceirização de maneira eficaz é preciso estabelecer uma 
relação de parceria para que sejam obtidas as informações necessárias, mas corre-se o risco de ser manipulado e absorvido por ela. Não se trata apenas de saber lidar com grupos de pressão, mas de ter competência em áreas extremamente complexas da tecnologia ou do mercado, em que a especialização torna-se obsoleta em pouco tempo (Trosa, 2001, p. 52). Os servidores devem estar aptos a avaliar os riscos, a fazer julgamentos cada vez mais precisos, a reconhecer os problemas, os interesses, as lógicas dos parceiros, a gerenciar a diversidade de atores envolvidos por meio de acordos progressivos, conhecer mercados, ser capaz de escutar, ter consciência dos limites e a escolher o melhor instrumento contratual para gerenciar o ajuste.

A operacionalização de programas que atendam a diferentes demandas dos cidadãos, fugindo da padronização e ampliando as soluções específicas, envolve muito além da capacitação, requer o enfrentamento de dilemas e a modificação de alguns pressupostos e normas estabelecidas em relação às políticas públicas ${ }^{27}$. A igualdade de procedimentos da burocracia, a mesma norma para todos, em geral tolhe a possibilidade de se pensar em igualdade de resultados, o que dificulta a adaptação do serviço ao cidadão (FERRAREZI; Sousa, 2003). Esse dilema caminha no bojo das reformas administrativas das últimas duas décadas e implica riscos de arbitrariedade e desigualdade no atendimento. Qual é o equilíbrio entre a eqüidade e o serviço especializado?

A maioria das propostas dessa lista assumir riscos, ter maior liberdade para escolher, adaptar e inovar - exige meios para a assunção de maior autonomia por parte do servidor e, ao mesmo tempo, exige mecanismos de visibilidade, controle e responsabilização pelos resultados ${ }^{28}$.
Essas são competências que não eram utilizadas no gerenciamento por insumos no passado e exigem tanto mudanças na legislação quanto na cultura organizacional e na atitude dos servidores públicos, mas não é possível esperar as mudanças legais para preparar as pessoas para lidarem com essas questões.

Além de maior liberdade ao servidor, seria preciso investir: no desenvolvimento de equipes não hierárquicas que legitimem e sustentem as decisões de seus membros e saibam lidar com sistemas complexos não homogêneos; em avaliações de resultados sistematizadas para prover de modelos e soluções que amparem a decisão ${ }^{29}$; nas chefias superiores para que permitam o fluxo de decisões pela hierarquia e dêem apoio; na ética pública para dar coerência e confiança em um sistema descentralizado (Trosa, 2001, p. 47-49).

A delegação, a desconcentração e a descentralização das políticas, o modelo contratualista e uma nova gestão pública são considerados práticas importantes para a renovação do Estado. É preciso dispor-se de vários meios para adaptação às mudanças, mas não é possível transpor um modelo único. De qualquer modo, a maioria das proposições feitas para a reforma da administração pública, na última década, aponta para o mesmo cenário, em que os servidores deverão ser preparados para tomar decisões em contextos cada vez mais complexos, o que exigirá a consideração das pressões, a reflexão sobre todos os aspectos envolvidos na situação, o autocontrole e a gestão para avaliar riscos, a capacidade de propor e debater, a flexibilidade e a adaptação à diversidade de situações.

A concepção do curso de formação inicial para a carreira de EPPGG, bem como os cursos de aperfeiçoamento para a 
promoção na carreira deverão ser constantemente avaliados para serem adaptados a essa complexidade crescente, aos novos desafios e às exigências dos cidadãos, cada vez mais participativos da vida pública.

\section{Considerações finais}

Pode-se afirmar que, apesar das descontinuidades administrativas, os cursos preservaram os objetivos gerais do projeto inicial da carreira, o perfil generalista e as policompetências na formação do EPPGG, a fim de permitir ao profissional visão abrangente, sistêmica e integrada dos complexos problemas da administração pública e instrumentos para a ação e interação generalizada no aparato estatal.

Percebe-se que as mudanças realizadas no curso de formação inicial proporcionaram respostas bastante adequadas, tendo em vista os problemas enfrentados em edições anteriores, os desafios contemporâneos da administração pública e a crescente complexidade dos problemas e das demandas da sociedade. Cabe ressaltar ainda que a formação da ENAP é coerente com os princípios e objetivos da Carta Iberoamerica de la Función Pública (2003), segundo a qual a profissionalização da função pública é condição necessária para a melhoria da qualidade dos serviços prestados pelo Estado aos cidadãos e para a promoção do desenvolvimento.

No entanto, persistem inúmeros desafios, dentre os quais se destacam o aprimoramento do ensino de aplicação e novas tecnologias; a ausência de quadro próprio de professores, o que dificulta a construção e aplicação de um plano pedagógico específico para a formação profissional; o esvaziamento dos quadros de servidores da Escola; a adaptação e o aperfeiçoamento de sistemas gerenciais de informações e gestão do conhecimento.

Um dos principais obstáculos a ser superado para as próximas edições relaciona-se ao ensino aplicado às práticas de gestão pública, uma vez que o estágio ${ }^{30} \mathrm{e}$ as oficinas de políticas públicas utilizados em formações anteriores, e muito bem avaliados, foram retirados do curso pelo órgão supervisor da carreira. Diante dessa ausência, o curso terá de incrementar estratégias pedagógicas ${ }^{31}$ que trabalhem temas e problemáticas de forma aplicada, exigindo-se a criação de estudos de casos e de jogos específicos para a administração pública brasileira, tarefa essa ainda pouco difundida entre nós.

A melhoria no relacionamento entre a coordenação e os alunos foi uma conquista importante, haja vista o impacto favorável na aprendizagem. O planejamento e a definição da gestão dos processos de trabalho contribuíram fortemente para essa melhoria, tendo-se ainda destacado a publicidade de informações e das regras, a entrega antecipada de material didático e a supervisão pedagógica das aulas. Com a supervisão da equipe foi possível gerenciar conflitos interpessoais, tão comuns em situações de concorrência, e garantir que o curso mantivesse um bom padrão de qualidade.

Atualmente, profissionais bem qualificados são muito requisitados pelos dirigentes do governo federal, particularmente os de carreira, que possuem formação em policompetências, como são os do caso analisado. Claro está que esse curso é apenas o início da trajetória, e os cursos de aperfeiçoamento, como condição para a promoção funcional, devem ser realizados tendo em vista as mudanças nas competências requeridas pelas organizações e a necessidade de atualização constante. Diferentes formas sob as quais 
a capacitação pode ser desenvolvida devem ser estimuladas, a fim de permitir maior adequação às características e necessidades dos profissionais, tais como: o ensino a distância, o desenvolvimento por meio de estudos e pesquisas, estágios em outras instituições/departamentos, benchmarking e treinamento em serviço.

A formação permanente do servidor que leve em consideração esses fatores e toda a complexidade discutida surtirá mais efeito, se houver uma política adequada de gestão de pessoas e uma propensão à aprendizagem pelo servidor, pela equipe e pela chefia e essa formação constituir um trabalho contínuo de aprendizagem crítica que permita analisar e questionar as práticas e saberes estabelecidos.

No entanto, há de se considerarem os limites da capacitação, uma vez que ela resolve apenas questões específicas, e não todos os tipos de problemas das organizações. Também é claro que as questões políticas, ideológicas e coorporativas pesam nas decisões e, na maioria das vezes, sobrepõem-se às prioridades diagnosticadas. Por esses motivos, a construção de um ethos da função pública é tão necessária, ao lado da reflexão crítica sobre o que constitui o interesse público.

(Artigo recebido em janeiro de 2006. Versão final em março de 2006) 


\section{Resumo dos temas que compõem os eixos do curso de formação inicial}

\begin{tabular}{|c|c|c|}
\hline EIXOS & $\begin{array}{l}\text { Disciplinas focadas em } \\
\text { Marcos analíticos e co- } \\
\text { nhecimentos }\end{array}$ & $\begin{array}{l}\text { Disciplinas focadas em } \\
\text { Instrumentos de análise e } \\
\text { gestão }\end{array}$ \\
\hline $\begin{array}{l}\text { 1- Estado, sociedade e } \\
\text { democracia ( } 52 \mathrm{~h})\end{array}$ & $\begin{array}{l}\text { D } 1.1 \text { - O Estado contemporâneo } \\
\text { e suas transformações (14h) } \\
\text { D } 1.2 \text { - Democracia e cidadania no } \\
\text { Brasil1(16h) } \\
\text { D } 1.3 \text { - Sistema político brasileiro } \\
\text { (20h) }\end{array}$ & \\
\hline $\begin{array}{l}\text { 2- Economia e desenvolvi- } \\
\text { mento } \\
(82 \mathrm{~h})\end{array}$ & $\begin{array}{l}\text { D } 2.1 \text { - Economia internacional (16h) } \\
\text { D } 2.2-\text { Economia brasileira ( } 28 \mathrm{~h}) \\
\text { D } 2.3 \text { - Economia do setor público } \\
(32 \mathrm{~h})\end{array}$ & \\
\hline $\begin{array}{l}\text { 3- Administração pública } \\
\text { (150h) }\end{array}$ & $\begin{array}{l}\text { D } 3.1 \text { - O debate contemporâneo da } \\
\text { gestão pública ( } 20 \mathrm{~h}) \\
\text { D } 3.2 \text { - Administração pública brasi- } \\
\text { leira }(20 \mathrm{~h})\end{array}$ & $\begin{array}{l}\text { D } 3.3 \text { - Direito Administrativo e } \\
\text { serviços públicos ( } 24 \mathrm{~h}) \\
\text { D } 3.4 \text {-Modelos de gestão e arquitetura } \\
\text { organizacional ( } 8 \mathrm{~h}) \\
\text { D } 3.5 \text { - Gestão de pessoas no setor } \\
\text { público (12h) } \\
\text { D } 3.6 \text { - Sistemas gerenciais de informa- } \\
\text { ção (8h) } \\
\text { D } 3.7 \text { - Gestão de contratos e licitação } \\
\text { (16h) } \\
\text { D 3.8- Planejamento e gestão financeira } \\
\text { e orçamentária (36h) }\end{array}$ \\
\hline $\begin{array}{l}\text { 4- Políticas públicas } \\
\text { (146h) }\end{array}$ & $\begin{array}{l}\text { D } 4.1 \text { Modelos de análise atuais e } \\
\text { conceituação( } 24 \mathrm{~h}) \\
\text { D 4.2-. Atores políticos, participação } \\
\text { e controles (16h) } \\
\text { D 4.3-Dilemas contemporâneos das } \\
\text { políticas públicas ( } 20 \mathrm{~h})\end{array}$ & $\begin{array}{l}\text { D } 4.4 \text { - Análise e interpretação de dados } \\
\text { e indicadores econômicos e sociais (16h) } \\
\text { D } 4.5 \text { - Planejamento estratégico ( } 24 \mathrm{~h}) \\
\text { D } 4.6 \text { - Elaboração e gerenciamento de } \\
\text { projetos (20h) } \\
\text { D } 4.7 \text { - Monitoramento e avaliação de } \\
\text { políticas públicas ( } 20 \mathrm{~h})\end{array}$ \\
\hline
\end{tabular}

Obs.: Nas 450 horas, não foram computados os períodos destinados a estudos, provas e ao ciclo de seminários (cerca de 30 horas). 


\section{Notas}

* Texto modificado do originalmente apresentado no Painel do CLAD - "Algunas experiencias nacionales en torno al esfuerzo de organizar el servicio civil a la luz de la Carta Iberoamericana de la Función Pública", em Santiago do Chile, outubro de 2005.

${ }^{1}$ Em 1986, com a reorganização da estrutura da Administração Pública Federal, foi extinto o Departamento de Administração do Serviço Público (Dasp), criado em junho de 1938, que deu lugar à Secretaria da Administração Pública (Sedap).

${ }^{2}$ A intenção do Dasp era analisar a viabilidade de criação de uma instituição oficial de ensino e treinamento no Brasil, inspirada na Escola Nacional de Administração (ENA) da França. Rouanet analisou comparativamente os modelos francês e alemão com os resultados da investigação de instituições de formação e treinamento existentes no Brasil.

${ }^{3}$ Rouanet apresentou um projeto com base nos modelos aplicados na França e na Alemanha. Propôs a criação de carreiras superiores múltiplas em todos os órgãos federais que não as tivessem; ou, como alternativa, a criação de uma carreira superior, a de Agente do Serviço Federal, baseada no modelo do administrador civil do sistema francês. Com essas propostas, segundo o autor, não se estaria "europeizando" o sistema administrativo brasileiro, mas criando "exclusivamente carreiras executivas" (Rounnet, 1982, p. 25).

${ }^{4}$ A ENAP foi criada pelo Decreto no 93.277 , de 19 de setembro de 1986, para ser "o pólo irradiador da Reforma Administrativa" que o governo do presidente José Sarney pretendia implantar, por meio da Secretaria de Administração Pública (Sedap). O objetivo da ENAP, definido no art. $2^{\circ}$ desse decreto, era "planejar, coordenar e avaliar as atividades de formação, aperfeiçoamento e profissionalização do pessoal civil de nível superior da administração federal".

${ }^{5}$ A carreira de EPPGG foi criada pela Lei no 7.834, de 6 de outubro de 1989, conforme o art. $1^{\circ}$ “[...] para execução de atividades de formulação, implementação e avaliação de políticas públicas, bem assim de direção e assessoramento em escalões superiores da Administração Direta e Autárquica".

${ }^{6}$ O Decreto no 98.895 , de 30 de janeiro de 1990 , regulamentou a lei que criou a carreira e foi revogado pelo Decreto no 5.176, de 10 de agosto de 2004.

7 "Essas características, enfatizadas pelo modelo americano, teriam se somado às características do modelo francês - particularmente à natureza prática do estágio - para compor um perfil generalista especialmente adequado ao ambiente político-administrativo instável, típico da nossa realidade e das sociedades em transição democrática" (PEtrucci et al., 1995, p. 226).

${ }^{8}$ A Secretaria do Planejamento da Presidência da República (Seplan), em janeiro de 1989, incorporou a Secretaria de Administração Pública da Presidência da República (Sedap). Uma das conseqüências dessa mudança foi a transferência da ENAP para a jurisdição da Seplan. Essa subordinação, segundo Petrucci (1995), teve implicações profundas na história da ENAP e dos EPPGG, podendo ser entendida como geradora fundamental do "acidentado processo da criação da carreira".

9 A disputa de espaço político-institucional na máquina burocrática, segundo Petrucci (1995), manteve-se acirrada mesmo após a primeira legalização da carreira. Alguns segmentos que forneciam funcionários para os quadros de alto nível da administração tentaram "novo golpe" contra a carreira, transformando os seus cargos em Analistas de Orçamento. Então, após longo trabalho promovido pelos gestores e pela Associação dos EPPGG (Anesp), em 1992, promoveu-se a restauração da carreira e dos cargos de EPPGG, por meio do art. 21 da Lei n ${ }^{\circ} 8.460 / 92$.

${ }^{10}$ O Plano Diretor da Reforma do Aparelho de Estado foi apresentado em 1995, definindo objetivos e estabelecendo diretrizes para a reforma da Administração Pública Brasileira. 
${ }^{11}$ Os cursos de formação da carreira de EPPGG, de responsabilidade da ENAP, constituem a segunda fase do concurso público, de caráter eliminatório, para o provimento de cargos. A primeira fase é feita por outras instituições especializadas.

${ }^{12}$ A $10^{a}$ e a $11^{a}$ edições do curso serão realizadas em 2006 , com algumas alterações no programa, visando aprofundar o ensino aplicado nos eixos de administração pública e políticas públicas (consulte o programa em <www.enap.gov.br>).

${ }^{13}$ Segundo Petrucci (1995), a Enap dispunha de pouco tempo para preparar o curso, contando somente com um corpo docente externo, devido à inexistência de uma equipe interna de professores, o que gerou alguns problemas no andamento do curso. Dentre as falhas, a deficiência na execução da etapa final, condensada em módulos intensivos, foi marcante.

${ }^{14}$ Passaram por essas diretorias, quatro Diretores-Gerais, dois Diretores de Ensino e quatro Diretores de Estágio até o final do curso.

${ }^{15}$ A justificativa era que, embora a burocracia tivesse sido criada no Estado liberal como resposta eficiente à administração patrimonialista, criando uma série de controles que imprimissem o caráter público das ações do Estado, ela foi, ao longo do século XX, subvertendo as razões para as quais fora criada, formando uma categoria social específica, que estabelece, entre seus membros, certas relações que tendem a autonomizar-se diante da sociedade como poder externo e acima dela e muito pouco orientada à prestação de serviços públicos aos cidadãos.

${ }^{16}$ O Programa e o Relatório Final dessa edição fazem referência ao desenvolvimento de uma atividade de "Mapeamento de Competências Profissionais", que resultou num levantamento das aprendizagens e dificuldades enfrentadas pelos participantes do curso de formação. Porém, não foi encontrada informação sobre o que significou esse mapeamento.

${ }^{17}$ Essas questões foram levantadas pelos alunos dos cursos anteriores e constam nos relatórios de avaliação final.

${ }^{18}$ Pesquisa realizada pela OCDE indica que o perfil de competências dos altos gerentes está mudando na maioria dos serviços públicos e que há uma mudança na ênfase por competências gerenciais mais amplas, bem distintas daquelas aptidões específicas dos especialistas e dos técnicos (OCDE. Gerenciando a alta administração pública: uma pesquisa em países da OCDE. Brasília, ENAP, 1999).

${ }^{19}$ Adaptado do relatório da Agência de Certificação Ocupacional (2004).

${ }^{20}$ A avaliação por módulo trata da opinião do participante sobre programação, apoio ao desenvolvimento do curso, aplicabilidade e utilidade do treinamento, resultados e desempenho do instrutor. A avaliação final trata da satisfação geral quanto a três aspectos: programação, coordenação e apoio, resultados esperados e aplicabilidade, além de incluir um trabalho em que os alunos discutem os principais aspectos, positivos e negativos, quanto ao desenvolvimento do curso.

${ }^{21}$ A proposta inicial era que houvesse mais 400 horas para o estágio e a realização de oficinas de políticas públicas, mas ela não foi aprovada pelo Ministério do Planejamento, Orçamento e Gestão, responsável pela gestão da carreira.

${ }^{22}$ Os eixos básicos, com adaptações de carga horária, também fazem parte da formação da carreira dos Analistas de Orçamento e Planejamento, uma vez que igualmente pertencem ao ciclo de gestão e, portanto, devem ter formação comum. No caso, o eixo específico deles é Planejamento e orçamento.

${ }^{23}$ Como houve mudanças significativas na forma e no instrumento de avaliação aplicado nos cursos de formação, ao longo do tempo, não se pode fazer a comparação quantitativa dos resultados entre as edições anteriores e a oitava e nona.

${ }^{24} \mathrm{Em}$ média, um curso de formação envolve cerca de 40 pessoas, entre professores, assistentes e palestrantes, sem incluir os técnicos que atuam nas atividades de integração, na avaliação final e nas apresentações sobre o trabalho realizado pelos ministérios. 
${ }^{25}$ Nesse sentido, outros subsistemas da gestão de pessoas deveriam intervir com ações próprias relativas à seleção, à análise do trabalho, à tecnologia a ser utilizada, às condições objetivas e subjetivas do trabalho, etc. Vários autores concordam que é com base nessas informações, na definição do perfil do cargo e nas competências que as ações de recrutamento, seleção, formação e treinamento deveriam ser desenvolvidas.

${ }^{26}$ A lista pode crescer muito tendo em vista o perfil genérico que todo profissional deve ter: responsabilidade, flexibilidade, adaptação a mudanças, capacidade de trabalhar em equipe, proatividade, policompetências, motivação, capacidade de trabalhar sob pressão, etc.

${ }^{27}$ Para responder à diversidade de necessidades dos cidadãos, o Estado tem recorrido ao terceiro setor, mas os instrumentos administrativos e legais para essa parceria, criados nos anos $30 \mathrm{e}$ 60, ainda não foram adaptados, e os poucos que foram enfrentam resistência das consultorias jurídicas, como é o caso do termo de parceria criado pela lei das OSCIP (Lei no 9.790/99), que aperfeiçoa o convênio e é mais rigoroso nos controles de resultados, com contrapartidas desburocratizantes e mecanismos de responsabilização de dirigentes (FERRAREZI, 2002).

${ }^{28}$ A obrigação de prestar contas é cada vez mais exigida pela sociedade como forma de controle e de se evitar a corrupção. Traduzir a accountability ainda é um objetivo de longo prazo.

${ }^{29}$ A capacidade de intercambiar informações, de aprender e de capitalizar inovações é provavelmente um dos problemas mais graves da administração pública (TrosA, 2001, p. 73).

${ }^{30}$ A Escola Nacional de Administração (ENA) da França, no curso de formação do administrador civil, destina um longo período para o estágio, intercalando-o com o curso, de modo a colocar os alunos em situações de responsabilidade real e fazê-los tomar consciência da realidade das práticas administrativas ao longo da formação (CHEMLA, 2005).

${ }^{31}$ Embora em diferentes proporções, a diretora de estudos da Escola Nacional de Administração (ENA) da França, Eliane Chemla, em palestra realizada na Enap em 22 de junho de 2005, refere-se a problemas parecidos. Segundo ela, "Como transmitir, de modo eficaz, conhecimentos e aptidões diversificadas; de que maneira adequar uma linguagem comum a alunos provenientes de diferentes horizontes, mas que trabalham juntos nas instituições; de que maneira mensurar conhecimentos e o savoir-faire (saber fazer) no final do curso, para classificá-los de acordo com seu mérito?”.

\section{Referências bibliográficas}

Carta Ibero Americana de la Función Pública. In: Conferência Iberoamericana de Ministros de Administração Pública e Reforma do Estado, 5. Bolívia: CLAD/ONUDESA, 2003. Disponível em: <www.clad.org.ve>.

ChemLA, Eliane. A reforma da formação para carreiras da ENA/França: como formar profissionais para a condução de mudanças na administração pública. Palestra proferida pela Diretora da ENA - França, realizada na Enap. Brasília, 22 de junho de 2005. Agência de Certificação Ocupacional. In: Reunião da CÂmara de Certificação Ocupacional de Profissionais da Gestão Pública, 2.Bahia, Fundação Luís Eduardo Magalhães, 2004.

Comissão dos Alunos do I Curso de Políticas Públicas e Gestão Governamental. In: Seminário de Avaliação - Documento final. Brasília: ENAP, 1989. Mimeografado. 
Escola Nacional de AdministraçÃo PúBlica. Curso de políticas públicas e gestão governamental - Proposta Curricular. Brasília, 1988. Mimeografado.

Brasília, 1996.

. Curso de políticas públicas e gestão governamental - Programa de formação.

. Relatório do curso de Formação para Carreira de Especialista em Políticas Públicas e Gestão Governamental. Brasília: ENAP, 1997. Mimeografado.

. Relatório do curso de Formação para Carreira de Especialista em Políticas Públicas

e Gestão Governamental. Brasília: ENAP, 1998. Mimeografado.

. Relatório do curso de Formação para Carreira de Especialista em Políticas Públicas

e Gestão Governamental. Brasília: ENAP, 1999. Mimeografado.

. Relatório do curso de Formação para Carreira de Especialista em Políticas Públicas e Gestão Governamental. Brasília: ENAP, 2001. Mimeografado.

. Relatório do curso de Formação para Carreira de Especialista em Políticas Públicas e Gestão Governamental. Brasília: ENAP, 2002. Mimeografado.

- Avaliação do $8^{\circ}$ curso de Formação para Carreira de Especialista em Políticas

Públicas e Gestão Governamental. Brasilia: ENAP, 2004. Mimeografado.

- Programa de Formação para Carreira de Especialista em Políticas Públicas e Gestão Governamental. Brasília: ENAP, 2004. Mimeografado.

FERrarezi, Elisabete. Saiba o que são organizações da sociedade civil de interesse público.. Brasília: Agência de Educação para o Desenvolvimento, 2002. (Coleção Prazer em Conhecer).

Ferrarezi, Elisabete; Sousa, Marcelo Álvares de. Promoção da cidadania: para quem ou com quem? Respublica, Brasilia, nov. 2003. Disponível em: <www.anesp.org.br>.

Morin, Edgar. Podemos reformar a administração pública? In: CONGRESO INTERNACIOnal del CLAD sobre la reforma Del Estado y de la Administración Pública, 2004. Madri: CLAD, 2004.

Nogueira, Marco Aurélio.Um Estado para sociedade civil. In: Temas éticos epolíticos da gestão democrática. São Paulo: Cortez, 2004. cap. 4.

OCDE. Gerenciando a alta administração pública: uma pesquisa em países da OCDE.

Brasília: ENAP, 1999.

Odelius, Catarina Cecília; Maluf, Maria Regina. A formação do administrador de empresas: breve retrospectiva histórica, tendências e perspectivas. Caderno de Administração da UnB, Brasília, n. 10.

Petrucci, Vera Lúcia; Santos, Maria Helena C.; Brito, Marcelo (Coord.). Escolas de governo eprofissionalização do funcionalismo. Brasillia: ENAP, 1995.

Rouanet, Sergio Paulo. Criação no Brasil de uma Escola Superior de Administração Pública (Relatório). Brasília, 1982, Mimeografado.

Trosa, Sylvie. Gestão pública por resultados: quando o Estado se compromete. Rio de Janeiro: Revan, 2001.

Villa-Alvarez, Florindo. Escola de governo e a eficácia da gestão pública. Brasília, 1990. Mimeografado. 


\title{
Resumo-Resumen-Abstract
}

\section{Formação de carreiras para a gestão pública contemporânea: o caso dos Especialistas} em Políticas Públicas e Gestão Governamental

\author{
Elisabete Ferrarequ e Adélia Zimbrão
}

O artigo analisa o curso de formação inicial para a carreira de Especialista em Políticas Públicas e Gestão Governamental (EPPGG), recentemente reformulado. Conclui-se que as mudanças realizadas no curso, tendo em vista os problemas enfrentados em edições anteriores, os desafios contemporâneos da administração pública, a crescente complexidade dos problemas e as demandas da sociedade, proporcionaram respostas bastante adequadas. No entanto, persistem inúmeros desafios, dentre os quais se destacam o aprimoramento do ensino de aplicação e novas tecnologias. Ao longo das nove edições do curso, percebe-se que os principais objetivos do projeto inicial da carreira permaneceram, mesmo com todas as descontinuidades administrativas. Preservaram-se o perfil generalista e as policompetências na formação do EPPGG, a fim de permitir ao profissional uma visão abrangente e integrada dos complexos problemas da administração pública e desenvolver a capacidade de analisar, decidir e buscar os melhores resultados em prol do cidadão, conduzindo as relações e as atividades profissionais de acordo com os princípios da ética pública.

Palavras-chave: formação de carreiras, ENAP, Especialistas em Políticas Públicas

Formación de carreras para la gestión pública contemporánea: el caso de los Especialistas en Políticas Públicas y Gestión Gubernamental

Elisabete Ferrarezi y Adélia Zimbrão

Este artículo analiza el curso de formación inicial para la carrera de Especialista en Políticas Públicas y Gestión Gubernamental (EPPGG), recientemente reformulado. Se concluye que los cambios realizados, teniendo en cuenta los problemas enfrentados en las ediciones anteriores, los retos contemporáneos de la administración pública, la cresciente complejidad de los problemas y de las demandas de la sociedad, han proporcionado respuestas muy adecuadas. Sin embargo, persisten numerosos desafíos, entre los cuales se destacan el perfeccionamento de la enseñanza de aplicación y nuevas tecnologías. A lo largo de nueve ediciones del curso, se observa que los principales objectivos del proyecto inicial de la carrera han permanecidos a través del tiempo, aunque con todas las discontinuidades administrativas. Se preservaron el perfil generalista y las policompentencias en la formación del EPPGG, a fin de permitir al profesional una visión amplia e integrada de los complejos problemas de la administración pública y desarrollar la capacidad de analizar, decidir y buscar los mejores resultados en pro del ciudadano, conduciendo las relaciones y las actividades profesionales de acuerdo con los principios de la ética pública.

Palabras-clave: formación de carreras, ENAP, Especialista en Políticas Públicas

Career training for the contemporary public management: the case of the Specialists in Public Policies and Governmental Management

Elisabete Ferrarezi and Adélia Zimbrão

This paper analyzes the recently reformulated initial training course destined to the career of Specialists in Public Policies and Governmental Management (EPPGG). The article concludes that the changes introduced in the course presented quite appropriate responses, given the problems faced in the earlier editions, the contemporary challenges of the public administration, the increasing 
complexity of the problems, as well as the growing expectations of the society. Many challenges, however, remain, particularly with regard to the improvement of the interaction between theoretical and practical training and the new technologies. Despite the administrative discontinuities, the main goals established in the initial project of the career seem to have remained unchanged thoughout the nine editions of the course. The course for EPPGGs preserved the generalist profile and its multicompetency, enabling these professionals to have a broadened and integrated vision of the complex problems confronted by the public administration, as well as to develop the skills to analyze, decide and search for the best possible results for the citizen, while conducting their professional relationships and activities in accordance to the priciples of the public ethics.

Keywords: career training, ENAP, specialists in public policies

\section{Elisabete Ferrarezi}

Socióloga, mestre em Administração Pública pela Fundação Getúlio Vargas de São Paulo e doutoranda em Sociologia na UnB. Pertence à carreira de Especialista em Políticas Públicas e Gestão Governamental desde 1996. Atualmente é coordenadora-geral da Formação de Carreiras da ENAP. Contato: < beferrarezi@terra.com.br>.

Adélia Cristina Zimbrão da Silva

Graduada em Psicologia pela UERJ (1995), especialista (lato sensu) em Sociologia Urbana pela UERJ (1998) e mestre em Administração Pública pela EBAP/FGV (2001). Integra a carreira de Especialista em Políticas Públicas e Gestão Governamental e exerce o cargo de Assessora Técnica da Coordenação Geral de Cursos de Especialização da ENAP. Contato: <adelia.zimbrao@enap.gov.br>. 